\title{
SHÄPE REVERSAL OF GE/SI DOMES TO PYRAMIDS VIA SI-GE INTERMIXING AND STRAIN REDUCTION
}

William L. Henstrom, Department of Physics, University of Mllinois at UrbanaChampaign, 1110 West Green Street, Urbana, IL 61801

Chuan-Pu Liu, Department of Physics, University of Illinois at UrbanaChampaign, 1110 West Green Street, Urbana, IL 61801

J. Murray Gibson, Materials Science Division, Argonne National Laboratory, 9700 South Cass Avenue, Argonne, IL 60439-4838

\section{January, 2000}

The submitted manuscript has
been created by the University of
Chicago as Operator of Argonne
National Laboratory ("Argonne")
under Contract No. W-31-109-
ENG-38 with the U.S. Department
of Energy. The U.S. Govemment
retains for itself, and others acting
on its behalf, a paid-up, non
exclusive, irrevocable worldwide
license in said article to reproduce,
prepare derivative works,
distribute copies to the public, and
perform publicly and display
publicly, by or on behalf of the
Govemment.

Distribution:

1-2. PRS

3. J. M. Gibson

4. L. E. Rehn

5. J. Coble

6. File

Conference Paper to be published in the proceedings of the Materials Research Society's Fall 1999 Meeting.

*Work supported by the U.S. Department of Energy through the Basic Energy SciencesMaterials Sciences under contract No. W-31-109-Eng-38. 


\section{DISCLAIMER}

This report was prepared as an account of work sponsored by an agency of the United States Government. Neither the United States Government nor any agency thereof, nor any of their employees, make any warranty, express or implied, or assumes any legal liability or responsibility for the accuracy, completeness, or usefulness of any information, apparatus, product, or process disclosed, or represents that its use would not infringe privately owned rights. Reference herein to any specific commercial product, process, or service by trade name, trademark, manufacturer, or otherwise does not necessarily constitute or imply its endorsement, recommendation, or favoring by the United States Government or any agency thereof. The views and opinions of authors expressed herein do not necessarily state or reflect those of the United States Government or any agency thereof. 


\section{DISCLAIMER}

Portions of this document may be illegible in electronic image products. Images are produced from the best available original document. 


\title{
CONFERENCE PAPER
}

\section{SHAPE REVERSAL OF GE/SI DOMES TO PYRAMIDS VIA SI-GE INTERMIXING AND STRAIN REDUCTION}

\author{
William L. Henstrom, Department of Physics, University of Illinois at Urbana- \\ Champaign, 1110 West Green Street, Urbana, IL 61801 \\ Chuan-Pu Liu, Department of Physics, University of Illinois at Urbana- \\ Champaign, 1110 West Green Street, Urbana, IL 61801 \\ J. Murray Gibson, Materials Science Division, Argonne National Laboratory, \\ 9700 South Cass Avenue, Argonne, IL 60439-4838
}

\section{January, 2000}

The submitted manuscript has
been created by the University of
Chicago as Operator of Argonne
National Laboratory ("Argonne")
under Contract No. W-31-109-
ENG-38 with the U.S. Department
of Energy. The U.S. Government
retains for itsell, and others acting
on its behalf, a paid-up, non
exclusive, irrevocable worldwide
license in said article to reproduce,
prepare derivative works
distribute copies to the public, and
perform publicly and display
publicly, by or on behalf of the
Govemment.

Conference Paper to be published in the proceedings of the Materials Research Society's Fall 1999 Meeting

\footnotetext{
*Work supported by the U.S. Department of Energy through the Basic Energy SciencesMaterials Sciences under contract No. W-31-109-Eng-38.
} 


\title{
SHAPE REVERSAL OF GE/SI DOMES TO PYRAMIDS VIA SI-GE INTERMIXING AND STRAIN REDUCTION
}

WILLIAM L. HENSTROM ${ }^{\dagger}$, CHUAN-PU LIU' ${ }^{\dagger}$, and J. MURRAY GIBSON ${ }^{\dagger}$

t Dept. of Physics, University of Illinois at Urbana-Champaign

‡ Materials Research Division, Argonne National Laboratory

\begin{abstract}
At $650^{\circ} \mathrm{C}$, Si freely intermixes with $\mathrm{Ge}$ in the dome islands causing a reduction in the strain of the islands and an increase in island size. The shape reversal of $\mathrm{Ge} / \mathrm{Si}$ domes to pyramids is investigated by analysis of the strain and size changes that occur on an island by island basis. This was carried out for anneal times of $0,20,40$ and 60 minutes. Transition islands were observed consistent with previous work[1], which are partially domes and partially pyramids. These islands demonstrated a strain gradient, having a slightly lower strain on the side that has transformed to a pyramid. Cross-sectional STEM was then used to show that this strain gradient is associated with a non-uniform Si intermixing in the islands.
\end{abstract}

\section{INTRODUCTION}

$\mathrm{Ge}$ and $\mathrm{SiGe}$ alloy islands on $\mathrm{Si}(001)$ have been studied extensively because they form to reduce strain energy in the epilayer in a classical Stranski-Krastanov (SK) fashion. These naturally forming islands are expected to enable new types of integrated circuits on traditional $\mathrm{Si}(001)$. This also serves as a model system for similar more complicated SK systems. However, despite it being used as a model there are several things that complicate even this system. First, different types of islands form depending upon coverage and growth temperature. Second, $\mathrm{Ge}$ and $\mathrm{Si}$ are completely miscible, allowing intermixing to occur freely if diffusion is given sufficient time.

T. I. Kamins, et al[1] showed that shape reversal from domes back to pyramids can occur by annealing the sample at $650^{\circ} \mathrm{C}$ for an extended period of time $(0,20,40$, and 60 minutes). They studied samples by AFM to understand the morphological changes. However, because these islands form in order to lower strain energy, understanding how strain changes between these samples, on an island by island basis, can help to shed light on the mechanisms for island formation and growth.

In this paper, we have taken the samples created by T. I. Kamins, et al[1], and done extensive TEM work on them to shed further light on what is happening as Si and Ge intermix at this elevated temperature. Ge islnds were grown by chemical vapor deposition in a lamp heated reactor. The islands were grown on top of a Si buffer layer and were deposited by $\mathrm{GeH}_{4}$ in $\mathrm{H}_{2}$ with a substrate temperature of $650^{\circ} \mathrm{C}$ during both the growth and anneal. The total Ge deposited was equivilant to 11 monolayers of relaxed Ge.

\section{STRAIN DETERMINATION}

Several techniques have been used to determine the strain in the Ge/Si and $\mathrm{SiGe} / \mathrm{Si}$ systems, such as: wafer deflection[2], low angle $X$-ray diffraction[1], cross-sectional TEM, CBED, and LACBED[3]. However, each of these techniques either provides only average data or is very cumbersome and difficult to perform. For these samples, strain was measured by a plan-view 2-beam dark field strain analysis and using the "Abrupt Displacement Model" $[4,5,6]$. By looking at the Howie-Whelan[7] equations for a 2-beam condition the strain is measured simply from the phase factor that deals with displacement

$$
\alpha=2 \pi \mathrm{g} \cdot \mathbf{R}
$$




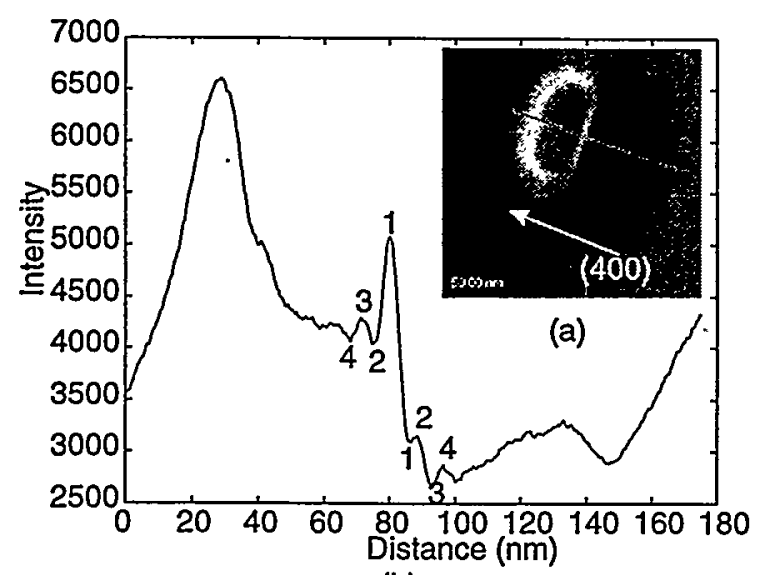

(b)

Figure 1: (a) shows a typical strain contrast image of a dome island using the (400) 2-beam condition with a scan line marked. (b) is the corresponding line scan with peak-trough pairs marked accordingly.

This phase, $\alpha$, then cycles through $\pi / 4,3 \pi / 4,5 \pi / 4$, etc. as the distance between the matching peak-trough pairs on either side of the line of minimum contrast increases (Figure 1 shows an image with its corresponding line scan with the peak-trough pairs numbered accordingly). $\mathbf{R}$ is taken to be a linear function in distance and strain inside the radius of the island and quickly falls off outside the radius similar to the Ashby-Brown work[8, 9]. We have shown[4] that this then gives the following relation for measuring strain within the island radius

$$
\varepsilon=\frac{\alpha_{n}}{2 \pi \mathrm{g} \cdot \mathbf{r}}=\frac{2 n-1}{4|\mathbf{g}| d_{n}}
$$

Where $n$ is the peak-trough pair number in Figure 1 and $d_{n}$ is the distance between the pair. This provides an easy method to measure strain island by island in plan-view TEM.

Figure 2 shows the average strain reduction as a function of time. Note how quickly the average strain decreases. At 0 minutes, the islands are almost completely domes with an average strain of 1.7, however, by 40 minutes the islands have become mainly pyramids with a greatly reduced strain of 0.3 . Therefore, after 40 minutes of annealling at $650^{\circ} \mathrm{C}$, Si has reduced the strain to less

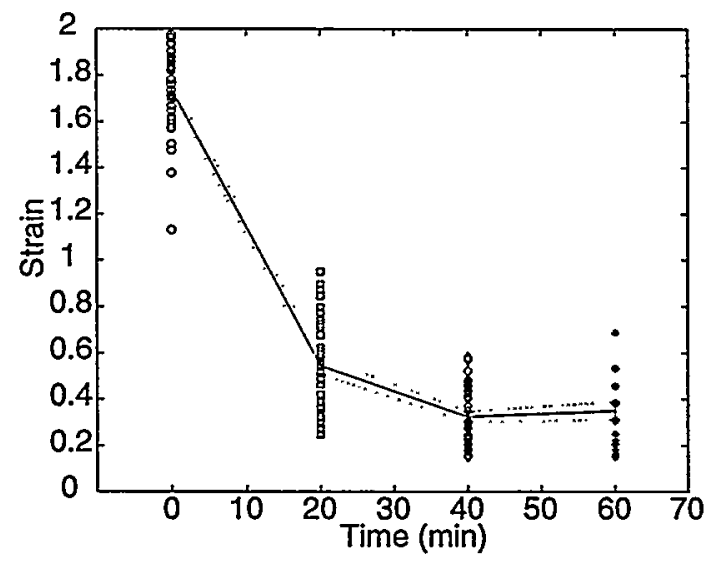

Figure 2: Strain measurements plotted as a fuction of time. The solid line denotes the mean value and the dashed lines denote the width of error. 
than $1 / 5$ its initial value.

\section{SUPPRESSED DIFFRACTION}

Suppressed diffraction is a new application of an old method. The mass-thickness contrast technique[11], that has been used for years on amorphous and biological samples, is applied to a crystalline system. It is done by tilting the sample into a very weakly diffracting condition[10, 12]. By doing this, the dominant effect in the image is that of incoherent elastic scattering. If the substrate is flat and roughly the same thickness in an area, we can then subtract off the amplitude change due to the substrate. The remaining amplitude variations are due solely to the island scattering, giving an inverted shape of the island itself. This can then be used to measure both the width of the island as well as the height, and therefore, the aspect ratio. This is very important since dome and pyramid islands have different aspect ratios.

Figure 3 shows the images and corresponding line scans for both a pyramid and a dome islands. As can be seen, this method can easily distinguish between domes and pyramids. Figure 4 shows a three-dimensional rendering of these same islands. By measuring the diameters of the islands

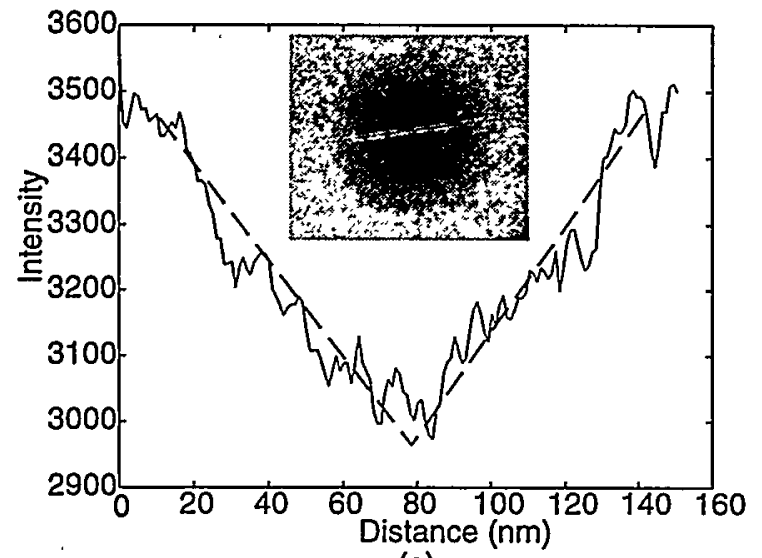

(a)



(b)

Figure 3: Suppressed diffraction image and its corresponding intensity line scan of (a) a pyramid island and (b) a dome island. The dashed lines approximate the actual pyramid and dome shapes, respectively.

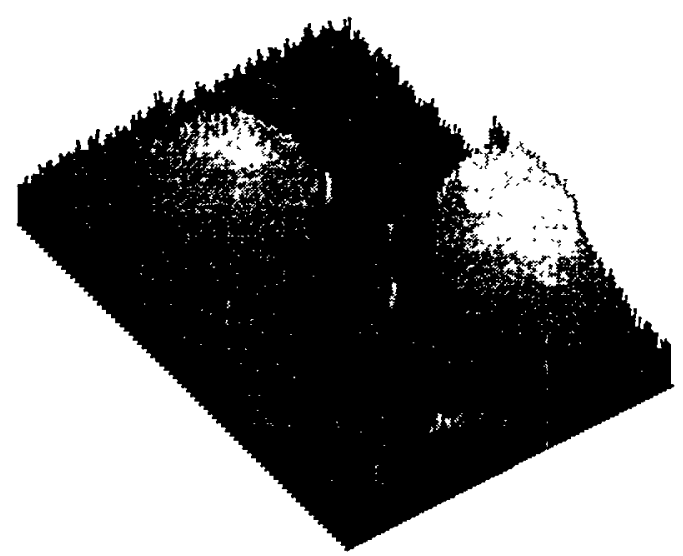

Figure 4: Three-dimensional rendering of a suppress diffraction image showing a pyramid and a dome islands. 


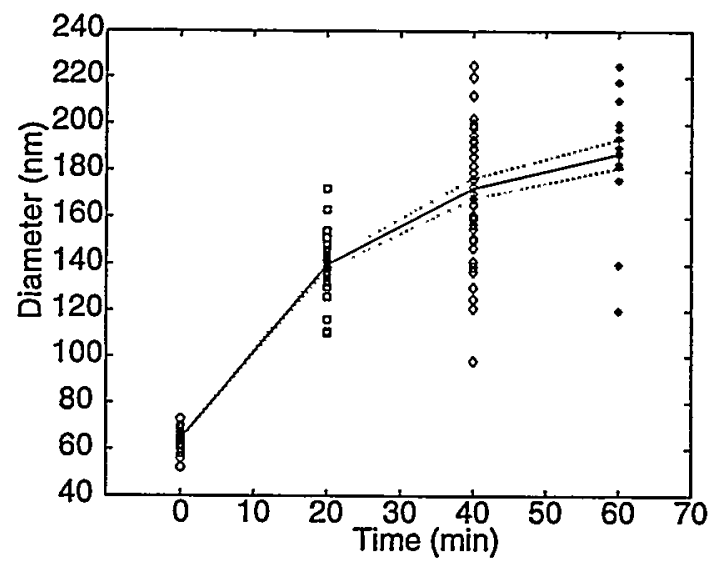

Figure 5: Diameter measured as a function of time by the suppress diffraction technique. The solid line denotes the mean value and the dashed lines denote the width of error.

in different samples, we obtain Figure 5. The diameter of these islands increases roughly as a function of $t^{1 / 2}$.

\section{TRANSITION ISLANDS}

As was noted in [1], there were observed transition islands as domes changed their shape back to pyramids. These islands have one side that looks like a dome and the other that looks like a pyramid. These islands were also easy to detect in our experiments. In the strain contrast measurement, the strain was slightly lower on one side of the island then it was on the other, as can seen in the spreading out of fringes on one side of the island (see Figure 6). In the suppressed diffraction condition, the shape of these islands was easily seen. Figure 7 shows an image, corresponding line-scan, and three-dimensional rendering of a transition island. Note the steep slope on the dome side and the gradual slope on the pyramid side.

From these results we concluded that these transition islands were caused by a non-uniform intermixing of Si into the islands. By having such a gradient of Si concentration, the side with less $\mathrm{Si}$ would be slightly more strained and would then relax back to the pyramidal shape at a later time. To verify this cross-sectional STEM with EDAX was performed on the samples to



Figure 6: Strain contrast image of a transition island. Note the larger distance between peak-trough pairs on the pyramid side versus the dome side, showing a lower strain on the pyramid side. 




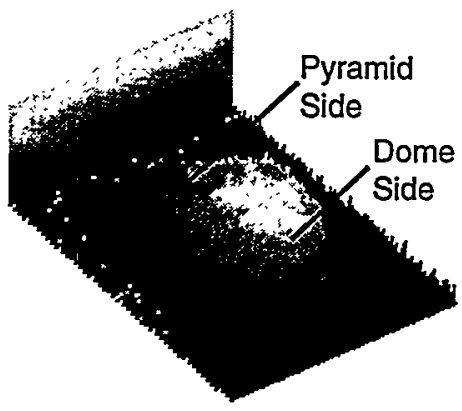

(b)

(a)

Figure 7: Suppressed diffraction image (a), its corresponding intensity line scan (b), and a threedimensional rendering of a transition island. The dashed line in (b) approximates the actual transition island shape.

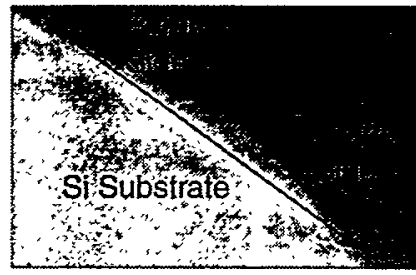

(a)

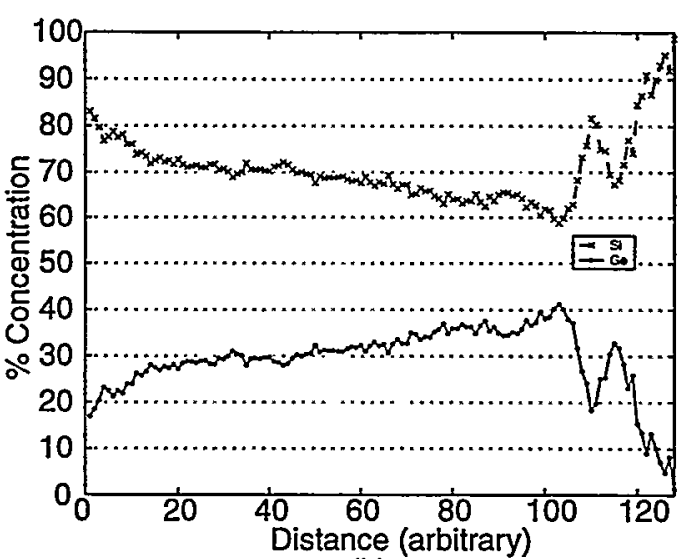

(b)

Figure 8: Z-contrast image showing EDAX line scan area (a) and the EDAX compositional analysis (b) showing a higher Si concentration on the pyramid side of the transition island by as much as $10 \%$ higher concentration.

quantify the concentration gradients if any. Figure 8 shows a Z-contrast image of a transition island along with the EDAX line scan across the image. On the pyramid side, Ge is roughly $30 \%$ of the concentration, and on the dome side, the Ge concentration has risen to approximately $40 \%$. This analysis was consistent on such islands.

\section{CONCLUSIONS}

At $650^{\circ} \mathrm{C}$, Si free intermixes with Ge domes. This intermixing causes a reduction in the strain making it energetically favorable for the islands to relax back to the pyramid shape[13]. The Si intermixing, however, is not done uniformly. This causes the islands to relax via a transition island that has a pyramid like side and a dome like side. Strain measurements showed that the pyramid side was slightly less strained than the dome side and cross-sectional STEM with EDAX showed that $\mathrm{Si}$ composition varied from the the pyramid side to lower on the dome side. 


\section{ACKNOWLEDGEMENTS}

Samples were provided by T.I. Kamins and R.S. Williams of the Quantum Structures Research Initiative at HP. This work is supported by the NSF focussed research group on "Naturally Patterned Nanostructures" under grant number DMR \#9705440. Samples characterization by TEM was carried out in the Center for Microanalysis of Materials, University of nlinois, which is supported by the U.S. Department of Energy under Grant No. DEFG02-96-ER45439. W.L. Henstrom would like to thank the Fannie and John Hertz Foundation for their financial support.

\section{References}

[1] T.I. Kamins, G. Medeiros-Ribeiro, D.A.A. Ohlberg, and R.S. Williams. Appl. Phys. A 67, 727 (1998).

[2] J.A. Floro, E. Chason, and S.R. Lee. edited by S.W. Pang Diagnostic Techniques for Semiconductor Materials Processing II. (Mater. Res. Soc., Pittsburgh, PA, 1996) pp.491-6. USA.

[3] A. Hovsepiam, D. Cherns, and W. Jäger, Inst. Phys. Conf. Ser. No. 153: Section 10, 413 (1997).

[4] P.D. Miller, Chuan-Pu Liu, and J.M. Gibson, submitted to Ultramicroscopy.

[5] P.D. Miller, C.-P. Liu, W.L. Henstrom, J.M. Gibson, Y. Huang, P. Zhang, T.I. Kamins, D. P. Basile, and R. Stanley Williams, Appl. Phys. Lett. 75, 46 (1999).

[6] C.-P. Liu, P.D. Miller, W.L. Henstrom and J.M. Gibson, Presented at MRS Spring Meeting, San Francisco, 4-9 April, to be published in MRS proceeding (1999).

[7] P.B. Hirsch, A. Howie, R.B. Nicholson, D.W. Pashley, and M.J. Whelan, Electron Microscopy of Thin Crystals, (Butterworths, London, 1965), p. 206.

[8] M.F. Ashby, and L.M. Brown. Phil. Mag. 8, 1083 (1963).

[9] M.F. Ashby, and L.M. Brown. Phil. Mag. 8, 1649 (1963).

[10] C.-P. Liu, P.D. Miller, W.L. Henstrom, and J.M. Gibson, submitted to J. Microscopy.

[11] Ludwig Reimer, Transmission Electron Microscopy: Physics of Image Formation and Microanalysis, 3rd ed. (Springer-Verlag, Berlin, 1993) pp. 138, 204-205.

[12] C.-P. Liu, W.L. Henstrom, and J.M. Gibson, Presented at MRS Fall Meeting, Boston, 28 November-3 December, to be published in MRS proceeding (1999).

[13] W.L. Henstrom, C.-P. Liu, J.M. Gibson, T.I. Kamins, and R.S. Williams, in preparation. 